\title{
Lusioersily
}

\section{The Mediating Role of Self-Regulation and Self-Efficacy on Physical Activity Change in Community-Dwelling Older Adults ( $>=65$ Years): An Experimental Cross-Lagged Analysis Using Data From SITLESS}

Mc Mullan, I., Bunting, B., Blackburn, N., Wilson, J., Deidda, M., Caserotti, P., Smith, L., Dallmeier, D., Roqué i Figuls, M., Weinmayr, G., Giné-Garriga, M., Coll-Planas, L., \& Tully, M. (2021). The Mediating Role of SelfRegulation and Self-Efficacy on Physical Activity Change in Community-Dwelling Older Adults (>=65 Years): An Experimental Cross-Lagged Analysis Using Data From SITLESS. Journal of Aging and Physical Activity, 29(6), 931-940. https://doi.org/10.1123/japa.2020-0322

Link to publication record in Ulster University Research Portal

Published in:

Journal of Aging and Physical Activity

Publication Status:

Published (in print/issue): 01/12/2021

DOI:

10.1123/japa.2020-0322

Document Version

Author Accepted version

\section{General rights}

Copyright for the publications made accessible via Ulster University's Research Portal is retained by the author(s) and / or other copyright owners and it is a condition of accessing these publications that users recognise and abide by the legal requirements associated with these rights.

\section{Take down policy}

The Research Portal is Ulster University's institutional repository that provides access to Ulster's research outputs. Every effort has been made to ensure that content in the Research Portal does not infringe any person's rights, or applicable UK laws. If you discover content in the Research Portal that you believe breaches copyright or violates any law, please contact pure-support@ulster.ac.uk. 
The mediating role of self-regulation and self-efficacy on physical activity change in community-dwelling older adults ( $\geq 65$ years): An experimental cross-lagged analysis using data from SITLESS

McMullan, I., Bunting, B., Blackburn, NE., Wilson, JJ., Deidda, M., Caserotti, P., Smith, L., Dallmeier, D., Roqué i Figuls, M., Weinmayr, G., Giné-Garriga, M., Coll-Planas, L. \& Tully, MA.

\begin{abstract}
Improving the capacity for physical activity interventions to maintain behaviour change is a key public health concern and an important strategy for the health and independence of older adults. Ways of ensuring effective maintenance of physical activity levels in older adults is unclear. This study includes the objective measure of moderate-vigorous physical activity (MVPA), selfreported self-efficacy, and self-regulation at four timepoints (baseline, intervention completion at 4 months, 12-, and 18-month follow-up) from the SITLESS study, a clinical trial conducted with a cohort of community-dwelling older adults ( $\geq 65$ years) from Denmark, Germany, Spain, and United Kingdom. A cross-lagged analysis found that self-regulation and self-efficacy may be key determinants of MVPA behaviour in community-dwelling older adults. More specifically, the use of behavioural support strategies represents an important correlate of MVPA behaviour, and its association with MVPA may be mediated by self -regulation and -efficacy in older adults in the short and long term.
\end{abstract}

\title{
Keywords
}

Self-efficacy; self-regulation; physical activity; social cognitive model. 


\section{Introduction}

Older adults are the fastest growing segment of the world's population, and preserving functional capability, cognitive performance, and independence remains a key health priority (WHO, 2011). Evidence suggests that physical activity plays an important role in the promotion and maintenance of mental and physical health in older adults through social, psychological, and biological mechanisms (Bangsbo et al., 2019; Cunningham et al., 2020; Fried et al; 2020; Silverman \& Duester, 2014; Zubala et al., 2017; WHO, 2014). Despite these benefits, most older adults fail to meet the physical activity guidelines of 150 minutes of moderate to vigorous physical activity (MVPA) on five or more days per week (CMO, 2019; DoHHS, 2018; Hallal et al., 2012; Murray et al., 2017; Rhodes et al., 2017). In fact, research shows that physical activity level in older adults declines with age (Lee et al., 2015). Furthermore, evidence shows that $12.5 \%$ of older adults over 55 years are physically inactive across Europe (Gomes et al., 2017). In the UK, 29\% of older adults aged between 65 to 74 years, and $52 \%$ aged 75 years or older are physically inactive (Sports England, 2019).

A widely used model for the promotion of physical activity involves the referral of insufficiently active individuals by their primary health care team to an exercise referral scheme (ERS). In the UK this usually involves a 12-week exercise programme carried out in a non-clinical environment such as a local leisure centre (DoH, 2011; NICE, 2014; Rowley et al., 2018). In general, evidence supports the health benefits of such programmes (NICE, 2014; Rowley et al., 2018), but suggests that health-related gains or increased physical activity levels are rarely sustained in the longerterm (Pavey et al., 2011; Murphy et al., 2012; Rowley et al., 2018) perhaps due to health-related issues or physical capability (Arnardottir et al., 2013; Franco et al., 2015). More specifically, ways of ensuring effective maintenance of physical activity levels in older adults at one year or beyond are unclear (Zubala et al., 2017). Therefore, improving the capacity for interventions such as ERS to achieve and maintain improvements in physical activity is a key public health concern and an important strategy for managing the health and independence of older adults (WHO, 2002).

Interventions underpinned by a behavioural theory have been shown to be more effective in maintaining physical activity (Dombrowski et al., 2016; Michie \& Abraham, 2004; McEwan et al., 2019; Rhodes et al., 2017), and one of the most applied theoretical approaches is social cognitive theory (SCT) (Bandura, 1986; 1997). SCT proposes that change in physical activity behaviour is achieved by two complementary paths: directly through changes in self-regulation, achieved through behaviour change strategies such as planning, scheduling, or self-monitoring; and indirectly via the effects of self-regulation on self-efficacy, the belief in one's own capabilities to carry out a course of action (Bandura, 1986; 1997; 2004). Empirical evidence supports this theory in younger adults where Teixeira et al.'s (2015) systematic review ( $n=6$ studies; range 25-44 years) found evidence (2/3 studies) for both paths; and Murray et al.'s (2018) systematic review ( $n=39$ studies; mean age 53 years) showed that self-regulation was significantly associated with physical activity both during the six months after baseline assessments ( $n=3 / 3$ studies, $100 \%)$, and also in the mid to long term (six months or later) 16 ( $n=1 / 1$ study, $100 \%)$ in young to middleaged adults.

Evidence supporting the efficacious of SCT in older adults is mixed. McAuley et al.'s (2011) study among 177 participants (mean age 66.44 years) suggests self-regulation strategies enhance selfefficacy, which in turn leads to sustained increase in exercise behaviour, a structured component of physical activity, at 11 months post intervention. In contrast, a systematic review carried out by French et al. (2014) ( $n=24$ studies; $\geq 60$ years) found that whilst physical activity interventions such as walking increased self-efficacy (effect size $(d)=0.37)$ and physical activity $(d=0.40)$, selfregulatory techniques such as goal setting and planning were associated with lower levels of selfefficacy and physical activity. This could be due to, for example decreased executive function or 
the lack of relevance of such techniques for older adults where older adults may have increased work or childcare responsibilities and so less time for physical activity planning. Further studies exploring the efficacy of components of SCT, such as self-regulation and self-efficacy in older adults are warranted.

The aim of this analysis was to assess the theoretical assumption that physical activity behaviour change is mediated by self-regulatory strategies and self-efficacy in older adults ( $\geq 65$ years) using objectively measured moderate to vigorous physical activity (MVPA) using an accelerometer, as well as self-reported measures of self-efficacy and self-regulation from the

\section{Methods}

This analysis is based on the SITLESS study, a multi-centre randomised controlled trial of exercise in community-dwelling men and women aged $\geq 65$ years from across Denmark, Spain, Germany, and the United Kingdom (Giné-Garriga et al., 2017). Participants were eligible if they were able to walk for $\geq 2$ min (with or without a walking aid); scored four or above on the Short 18 Physical Performance Battery (SPPB) (Guralnik et al., 1995); were inactive, defined as engaging in $\leq 30$ minutes of moderate intensity physical activity five days per week; and/or spent 6-8 hours per day sitting. Participants were excluded if they had three or more errors on a six-item cognitive impairment questionnaire to identify moderate or severe dementia; suffered from unstable medical conditions (e.g. elevated blood pressure after medication, uncontrolled hypertension) or symptomatic cardiovascular diseases that contraindicate participation in physical activity; could not commit to attend $75 \%$ of the exercise referral scheme (ERS) sessions throughout the intervention; and/or had participated in an ERS in the six months prior to their entry into the study. A total of 2,660 older adults indicated their willingness to participate across the four countries via media (letters and social media), general practitioners and other health professionals from primary care, and senior centre community groups. Of those, $45.15 \%$ did not enter the study $(27.3 \%$ of those were excluded based on eligibility assessment). A total of 1,360 older adults were included at baseline.

\section{The intervention}

The participants were randomly divided to one of three groups - two intervention groups (Group 1 and 2), and a control group. Group 1 attended an exercise programme and received behavioural change support. The exercise programme ran over four months and involved two sessions per week of 45-60 minutes of aerobic, strength-based, balance and flexibility activities. Behavioural change support focused on implementing various strategies to reduce sitting time while increasing physical activity and consisted of a) a one-to-one session, six group-based sessions, and four telephone calls; b) goal setting with a pedometer and activity diary (i.e. monitoring daily number of steps and/or time in physical activity); c) encouraging participants to use support from friends and family to help them reach the goals they set for themselves; and d) problem solving techniques were provided to help participants identify and respond to barriers they faced when changing their behaviour. Group 2 attended the exercise programme only. The control group attended two healthy living advice sessions only, one during the first four months post baseline, 20 and one four months later.

Participants were assessed and data was collected at the start of the study (timepoint one), at intervention completion at 4 months (end of intervention; timepoint two), at 12-month follow-up (timepoint three), and at 18-month follow-up (timepoint four). Further details can be found in the study protocol (Giné-Garriga et al., 2017). Informed by the MRC Framework for developing, evaluating, and implementing complex interventions (Craig et al., 2013), SITLESS has been approved by the various Ethics and Research Committees of each intervention site. Participation was voluntary and all participants provided informed consent before the start of the study. 


\section{Measures}

This study uses each of the following measures at each assessment point:

\section{Self-efficacy}

Perceptions of confidence to adhere to physical activity over time, overcoming potential barriers, and to accumulate physical activity was assessed using the Marcus Self-efficacy Questionnaire (Marcus et al., 1992) (reliability of 0.38 to 0.76; Resnick \& Jenkins, 2000), which asks how confident individuals are that they can be physically active when: i) tired, ii) in a bad mood, iii) they don't feel they have time, iv) on holiday, and v) it's raining or snowing, on a scale of 1 to 5 11 ( 1 is not confident and 5 is extremely confident). The score range is 1 to 25 where a high score in this analysis indicates a high level of self-efficacy.

\section{Self-regulation}

The 12-item Physical Activity Self-Regulation scale (PASR-12) (Umstattd et al., 2009) (reliability of 0.79 to 0.95 ; Watanabe et al., 2018) includes six components, each with two questions relating to self-regulation strategies such as self-monitoring, goal setting, eliciting social support, reinforcement, time management, and relapse prevention. Items are rated from 1 (never) to 518 (very often). The score range is 1 to 60 where a high score in this analysis indicates a high level 19 of self-regulation.

\section{Moderate-vigorous physical activity (MVPA)}

All participants were asked to wear an accelerometer (ActiGraph wGT3X-BT+; Actiraph, LLC, Pensacola, FL) on their dominant hip during waking hours for seven consecutive days and were told to remove it during any water-based activities such as bathing or swimming, and during sleep time. The devices were initialised to collect data at the default $30 \mathrm{~Hz}$ sampling rate (Brønd, \& Arvidsson, 2016) and analysed using ActiLife v6.13.3 software. The normal filter was utilised and data summarized using 10-second epochs (Wilson, Skjødt, et al., 2020). Non-wear time was defined using the Choi, Liu, Matthews, \& Buchowski (2011) algorithm which uses a window system, a 90-minute window for checking for consecutive zero counts and another 30 minute upand down- stream window for checking for more than 2 minutes of non-zero counts (Choi et al., 2011). The study included the results from participants with at least four valid days including at least one weekend day (Ricardo et al., 2019; Migueles et al., 2017). Furthermore, to be included each day had to include at least 600 minutes (10h/day) of wear time as in previous studies as recommended (Migueles et al., 2017). Physical activity was measured in daily counts per minute (CPM) where MVPA was >2020 CPM. This study uses the measure of average daily MVPA where a higher score indicates a higher level of MVPA.

\section{Covariates}

Evidence suggests that age, and sex affects physical activity levels (NHS Digital, 2019) and so the demographic variables of age (years), and sex (male/female) have been included in the analysis. Additionally, poor health is also a key determinant of physical activity (Franco et al., 2015) and so the 12-Item Short Form Survey (SF-12) score for both mental and physical health was included in the analysis (summary score 1 to 100).

\section{Analysis}

Characteristics of the study population were summarised using descriptive statistics. To investigate the associations between self-efficacy, self-regulation and MVPA over four time points (baseline, intervention completion at 4 months, and 12- and 18-month follow-up) a multigroup analysis within a cross-lagged modelling approach was used where the parameters are constrained to be equivalent across groups. The model consisted of a measurement model (confirmatory factor analysis) and a structural model (Figure 1). Adjustments for covariates based 
on existing literature was made (Franco et al., 2015; NHS Digital, 2019). To investigate the underlying psychological mechanisms responsible for statistical significance in the cross-lagged analysis a series of Wald tests were carried out (Polit, 1996). To account for the geographical stratification within each country (Denmark, Germany, Spain, and United Kingdom), the stratified variable of 'country' was included in the analysis. Model parameters were estimated from raw data using a robust maximum likelihood approach which is robust to non-normality (Enders, 2013; Yaun \& Bentler, 2000).

Data was analysed using an intention-to-treat strategy, where data on at least one occasion was present. Missing data was assumed to be missing at random, and the analysis was conducted using full information maximum likelihood, where model parameters were estimated directly (without imputation). Model fit was evaluated using a Root Mean Square Error of Approximation (RMSEA) $\leq 0.05$ with an upper limit $(90 \% \mathrm{Cl}) \leq 0.08$; a Comparative Fit Index $(\mathrm{CFI}) \geq 0.95$; a Tucker Lewis Index (TLI) $\geq 0.95$; and a Standardised Root Mean Square Residual (SRMR) $\leq 0.08$ (Hoyle, 1995). Where the levels of fit indices were not achieved, the modification indices were examined, and where appropriate, adjustments were made. Statistical significance was set at $p<0.05$. All analysis was conducted in Mplus (version 7.4; Muthen \& Muthen, Los Angeles, CA).

\section{Results}

Descriptive statistics have been calculated and are shown in Table 1. In brief, the sample analysed consisted of 1,360 participants (mean age 75.18 years; $62 \%$ female). On average participants spent 23 minutes per day engaging in MVPA (baseline). Average self-rated health scores (SF-12) were 44.96 for physical and $\mathbf{5 1 . 8 2}$ for mental health, which according to reported reference scores for older adults indicated generally good physical and mental health in our study population (Ware et al., 1996). The sample included older adults from Spain (26\%); United Kingdom (24\%); Denmark (25\%); and Germany (25\%). Participants scored on average 31.05 out of 60 on self-regulation, and 14.12 out of 25 on self-efficacy at baseline.

The measures of self-efficacy and self-regulation were invariant (equal) across all time points. The fit statistics showed that the model fitted the data well with a Root Mean Square Error of Approximation $\leq 0.05$ (RMSEA $=0.03 ; 90 \% \mathrm{Cl}=0.03,0.04$ ), and a Standardised Root Mean Square Residual $\leq 0.08$ (SRMR=0.06). The Comparative Fit Index $(\mathrm{CFI}=0.93)$ and Tucker Lewis Index $(T L I=0.92)$ were slightly less than the recommended 0.95 . Potentially the model could be fitted by the conventional criteria but given the good RMSEA result it was decided not to introduce any additional correlated residuals because there was no theoretical justification.

The mean difference was tested for each measure across all timepoints. The results showed that there was no mean difference for MVPA between groups across time; that the mean difference for self-regulation was lower than Group 1 at timepoint two (intervention completion at 4 months) for both Group 2 (Est=-0.33, SE=0.12), and control group (Est=-0.61, SE=0.12), and additionally for control group at timepoint three (Est=-0.27, SE=0.14) and four (Est=-0.25, SE=0.14); and the mean difference for self-efficacy was lower than Group 1 at timepoint one for Group 2 (Est=-0.21, $\mathrm{SE}=0.06)$ and control group (Est=-0.21, $\mathrm{SE}=0.06)$.

\section{Direct effects}

The results from the cross-lagged analysis is summarised in Table 2 and are described below.

Figure 1 - paths $A, B, C, D, E$ and $F$

Table 2 shows that the measures of MVPA, self-regulation, and self-efficacy are statistically significantly associated across all timepoints in all groups (Figure 1, path A, B, and C). The direct 
effect between Group 1 and control group is statistically significant between timepoints one and two for MVPA (Wald=8.78; $p<0.005$ ); for self-regulation (Wald=5.02; $p<0.05$ ); but not for selfefficacy at the end of the intervention (4 months). The direct effect is also statistically significant across timepoints two and three between Group 1 and control group for self-regulation (Wald=11.99; $p<0.005$ ); and Group 2 and control group for self-efficacy (Wald=14.97, $p<0.005$ (12-month follow-up).

Additionally, Table 2 shows that self-regulation has a statistically significant direct effect on MVPA at each timepoint for Group 1 (time 1: $E s t=0.01, S E=0.01$; time 2: $E s t=0.11, S E=0.06$; time 3: $E s t=0.26, S E=0.09$; and time 4: $E s t=0.15, S E=0.08$ ), but only for Group 2 (Est=0.25, $S E=0.06$ ) and control (Est=0.23, SE=0.08) at timepoint three (Figure 1, path D).

Self-regulation also has a statistically significant direct effect on self-efficacy at timepoint one for all groups (Group 1: Est=0.09; $S E=0.03$; Group 2: Est=0.19, SE=0.03; and control: Est=0.10, $\mathrm{SE}=0.03$ ); at timepoint two for both intervention groups (Group 1: Est=0.11, SE=0.04; Group 2: $\mathrm{Est}=0.12, \mathrm{SE}=0.05)$; and at timepoints three (Est=0.12, $\mathrm{SE}=0.05)$, and four $(\mathrm{Est}=0.24, \mathrm{SE}=0.07)$ for Group 2 only (Figure 1, path E). The direct effect was significant between Group 2 and control at timepoint one (Wald=4.29; $p<0.05$ ) (intervention completion at 4 months).

Furthermore, self-efficacy was not statistically significant for MVPA at any timepoint excluding timepoint one (Est=0.03, SE=0.02) (Figure 1, path F).

Figure 2 - paths 1, 2, 3, 4, 5, and 6

These paths were included to investigate the total effects in the model but showed a discontinuity of results between timepoints.

Indirect and total effects

Self-regulation had a statistically significant total effect on MVPA via the effect of self-efficacy within the same timepoint for Group 1 at timepoint one (Est=0.02, SE=0.01), and two (Est=0.13, $\mathrm{SE}=0.06$ ). It is statistically significant at timepoint three for all groups (Group 1: Est $=0.26$, $\mathrm{SE}=0.09$; Group 2: $E s t=0.25, \mathrm{SE}=0.06$; and control: $\mathrm{Est}=0.22, \mathrm{SE}=0.07$ ) (Figure 1, path $E^{\star} F+D$ ). The direct effects between groups was not statistically significant at timepoint three.

Additionally, Table 2 shows that self-regulation has a statistically significant effect on MVPA between timepoints one and two for both intervention groups (Group 1: Est=1.01, SE=0.28; Group 2: Est=0.41, $S E=0.21$ ); between timepoints two and three for all groups (Group 1: $E s t=1.85, \mathrm{SE}=0.54$; Group 2: $\mathrm{Est}=1.38, \mathrm{SE}=0.34$; control: $\mathrm{Est}=0.87, \mathrm{SE}=0.34$ ); and between timepoints three and four for Group 1 only $(E s t=1.40, S E=0.51)$ (Figure 1, path $\left(E^{*} A\right)+\left(E^{*} F^{*} A\right)+$ $\left.\left(B^{\star} D\right)+\left(B^{\star} E^{\star} F\right)+\left(E^{\star} C^{\star} F\right)\right)$. The direct effect was statistically significant between Group 2 and control between timepoints two and three (Wald=4.00, $p=0.05)$ (18-month follow-up).

Also, self-regulation (Est=0.15, $\mathrm{SE}=0.06)$ and self-efficacy $(\mathrm{Est}=0.34, \mathrm{SE}=0.16)$ at timepoint one had a statistically significant total effect on MVPA at timepoint four via its effect on MVPA at timepoint one for Group 1 only (18-month follow-up).

\section{Covariates}

Self-rated health was statistically related to self-efficacy $(p<0.05)$ for all groups (intervention group one: $E s t=0.02, S E=0.01$; intervention group two: $E s t=0.02, S E=0.01$; control group: $E s t=0.03$, $\mathrm{SE}=0.01)$; for self-regulation in the control group only $(E s t=0.02, S E=0.01)$; and for MVPA level in all groups (intervention group one: $E s t=0.01, S E=0,00$; intervention group two: Est=0.01, 
$\mathrm{SE}=0.00$; control group: $\mathrm{SE}=0.01, \mathrm{SE}=0.00$ ). Participants with poor health had lower self-efficacy, lower self-regulation, and lower MVPA levels.

Age was also statistically significant for MVPA level in all groups (intervention group one: Est=0.13, SE= 0.02; intervention group two: $E s t=-0.09, S E=0.01$; control group: $E s t=-0.08, S E=$ 0.01 ) where much older adults had lower levels of MVPA.

Additionally, sex was statistically significant for MVPA levels only in intervention group one (Est=0.04, SE=0.02) where females had lower levels of MVPA.

\section{Discussion}

Summary of findings

This is one of a few studies to examine the mediating effect of self-regulation and self-efficacy in physical activity interventions over time using a large population of community-dwelling older adults across four European countries (Bully et al., 2015; Zubala et al., 2017). A cross-lagged analysis was tested to investigate whether self-regulation and self-efficacy mediate change in MVPA; and how this relationship changed over time, controlling for the covariates of age, sex, country of residence and self-reported health. Overall, whilst the difference between a multicomponent intervention (incorporating both behavioural change support strategies and an exercise programme) and an exercise only intervention has not been confirmed to be statistically significant, the analysis showed that a multi-component intervention maintains MVPA via selfregulation or self-efficacy in the short-term (intervention completion at 4 months) (total effects: Est=0.13; $S E=0.06$ ); and may have potential implications for MVPA change in the longer-term (18-months follow-up) (total effects: Est=0.26; SE=0.09) for older adults.

Firstly, the results suggest that, within the context of the model, a multi-component SITLESS intervention that includes both exercise and behavioural change support strategies, enhances the relationship between MVPA across time (intervention completion at 4 months) over and above an exercise only programme (baseline) (Wald=8.78; $p<0.005$ ). This may be because of the psychological support offered in multi-component interventions in helping change every day routines, which may build on the intentions and motivations of participants entering an exercise programme (Schwarzer, 2008). This finding is supported by Zubala et al.'s (2017) review of reviews exploring the effects of physical activity interventions $(n=19$ reviews; mean age 59.8 to 79 years) which found that multi-component interventions had small to moderate effects (Cohen $5)=0.37$ ) on both objective and self-reported physical activity adherence in older adults.

Additionally, Bandura et al.'s (1986; 1997) SCT posits that behaviour is both directly influenced by self-regulation, and indirectly via the effects of self-regulation on self-efficacy. Similarly, previous research among 177 older adults (mean age 66.44 years) found that self-regulatory practices had a significant association with objectively measured physical activity adherence via the effect on self-efficacy (Est=0.07, SE=3.70) up to 11 months (McAuley et al.'s, 2011); and Rhodes et al.'s (2020) review ( $n=51$ studies) found that whilst overall physical activity interventions are capable of making changes within the small effect size range $(r=0.16)$ to key variables within SCT, the largest effect estimates were between physical activity and behaviour regulations ( $r=0.29 ; 95 \%$ Confidence Intervals $(\mathrm{Cl})$ : $0.14,0.43)$. Our analysis also found that whilst the difference in MVPA between a multi-component and an exercise only intervention has not been confirmed to be statistically significant, our multi-component intervention had a significant association with MVPA in older adults directly through changes in self-regulation (direct: Est=0.11; $S E=0.06$ ), or indirectly via the effects of self-regulation on self-efficacy in the short-term (indirect: $\mathrm{Est}=0.13$; $\mathrm{SE}=0.06$ ) (intervention completion at 4 months). 
Furthermore, whilst previous research supports the predictive capability of self-regulation for physical activity behaviour in the general population over time (Murray et al., 2018; McEachan et al., 2016; Rhodes et al., 2020; Young et al., 2014), studies in older adults suggest that there is no association. Research suggests that cognitive decline associated with the ageing process may limit the ability to exert control over, or self-regulate behaviour resulting in non-adherence to exercise programmes (Kwasnicka et al., 2016). Additionally, recent reviews by DevereauxFitzgerald et al. (2016) ( $n=14$ studies; >65 years), and Zubala et al. (2017) ( $n=19$ studies; >50 years) suggest that enjoyment driven by social connectedness, and not cognitive strategies, is a key determinant for physical activity maintenance in older adults. In contrast, this analysis showed a longer-term association between the measures of self-regulation and MVPA (18-month followup). The differences in the findings may be due to the composition of the intervention where for example, encouragement from friends and family was one of the components included in the behavioural support strategies which may have confounded the findings. Additionally, the longterm influence of self-regulation should be considered with caution, because the results show that both exercise only and control groups also showed an association between the measures of selfregulation and MVPA at 12-month follow-up suggesting that the results could be independent of the intervention. Therefore, self-regulatory strategies may be beneficial in physical activity promotion, but further research needs to explore 13 the potential of such strategies for older adults over the long-term in terms of changing physical 14 activity behaviour.

Evidence supporting the importance of self-efficacy as a predictor of long-term physical activity maintenance is mixed. A recent review in the general population by Rhodes et al. (2020) $(n=51$ articles; $n=20,000$ participants) found no association between self-efficacy and physical activity adherence. In contrast, McAuley et al. $(2003 ; 2007)$ reported an association between stronger self-efficacy and higher levels of physical activity at two and five-year follow-up ( $\mathrm{N}=174$ participants; mean age 66.7 years at baseline); and Schwarzer et al. (2008) ( $\mathrm{N}=835$ participants) found that stronger self-efficacy was associated with an increased maintenance of physical activity at four, eight, and 12-month follow-up. Our analysis supports that self-efficacy has an association with MVPA in the longer term (18-month follow-up) via its effect on MVPA at baseline (total effects: $E s t=0.34$; $S E=0.16$ ), suggesting that multi-component interventions affect selfefficacy which sustains MVPA over the longer-term. Future studies should include an intervention mechanism to directly explore associations of self-efficacy over time (Rhodes \& Blanchard, 2007).

Strength and limitations

Previous studies have highlighted that physical activity levels from interventions are rarely sustained and ways of maintaining these levels in older adults are unclear. A key strength of this study is that it adds to our understanding of which intervention components can maintain changes in physical activity in a rapidly ageing society (Pavey et al., 2011; Murphy et al., 2012; Rowley et al., 2018; Zubala et al., 2017). It also explores the underlying mechanisms using a cross-lagged analysis which simultaneously estimates both direct and indirect associations therefore enabling exploration of the reciprocal relationship between MVPA, self-regulation, and self-efficacy using data over four timepoints and up to 18 months' duration. This approach provides a more rigorous examination of the theoretical principles that can help understand how and why interventions succeed or fail (Bully et al., 2015). Furthermore, this analysis uses confirmatory factor analysis (CFA) (configural, metric, and scalar invariance) to address reliability and variance of the measures of self -regulation and -efficacy and so increases the robustness of the findings (Hays et al., 1994; Selig \& Little, 2012). Additionally, using an accelerometer to measure physical activity overcomes some of the bias introduced by self-reported measures which may be influenced by health status, mood, depression, anxiety, or cognitive ability, as well as seasonal variation, and social desirability (Dyrstad et al., 2014; Murphy, 2009; Saelens et al., 2012). 
However, whilst considering the contribution of this study, it is important to acknowledge some of the possible limitations that might influence the interpretation of the data. Firstly, a limitation of any study is selection bias, where individuals volunteering may have increased levels of motivation and capacity for change than the general population which may lead to higher levels of physical activity and so more biased results (Munafò et al., 2017; Kwasnicka et al. 2016; Rhodes et al., 2020; Wade et al., 2018). For example, the SITLESS population showed high levels of MVPA (22.80 minutes) per day therefore exceeding PA guidelines. Additionally, the sample is composed of primarily females (62\%) and descriptive statistics show that the sample are in good health (SF-12 scores are 44.96 for physical and 51.82 for mental; Ware et al., 1996) which make generalisation of the results difficult. Also, the model assumes that all the important predictors are included in the analysis, but there are many possible determinants of human behaviour (e.g. marital status, pain, comorbidities etc.) which may potentially confound the study's findings, a common issue in most studies (Selig \& Little, 2012). Furthermore, the model includes repeated measures across time which may give rise to a retest effect, where participants react to repeated questioning in the same way or try to meet the interviewer expectations (Selig \& Little, 2012).

\section{Conclusion}

Our results indicate that self-regulation strategies and self-efficacy may be key determinants of physical activity behaviour in community-dwelling older adults by maintaining physical activity in the short-term. Importantly, the use of behavioural support strategies, represents an important correlate of physical activity behaviour, and its association with physical activity may be mediated by both self -regulation and -efficacy in older adults over the short and long term. The longer-term influence of self-regulatory strategies need to be further explored. These findings should be considered when designing optimal behavioural interventions that target physical activity change in older adults.

\section{Acknowledgements}

The authors wish to express their appreciation for all those that volunteered for this study and Mrs Nicky Laird for her administrative support. We also thank the Northern Ireland Clinical Research Facility and the Municipality of Odense for facilitating the assessments in the United Kingdom and Danish sites, respectively. The work described in this publication was part of the SITLESS project, supported and funded by the European Union program Horizon 2020 (H2020Grant 634270). Consortium members of the participating organizations of the SITLESS project: Antoni Salvà Casanovas, Àlex Domingo, Marta Roqué and Laura Coll-Planas: Health and Ageing Foundation of the Autonomous University of Barcelona, Spain; Maria Giné-Garriga, Miriam Guerra-Balic, Carme Martin-Borràs, Javier Jerez-Roig, Guillermo R Oviedo, Marta SantiagoCarrés, Oriol Sansano and Guillermo Varela: Faculty of Psychology, Education and Sport Sciences Blanquerna, Ramon Llull University, Barcelona, Spain; Emma Mclntosh and Manuela Deidda: Health Economics and Health Technology Assessment, University of Glasgow, UK; Dietrich Rothenbacher, Michael Denkinger, Katharina Wirth, Dhayana Dallmeier and Jochen Klenk: Institute of Epidemiology and Medical Biometry, Ulm University, Germany; Frank Kee: Centre for Public Health, School of Medicine, Dentistry and Biomedical Sciences, Queen's University Belfast, UK; Mark A Tully, Jason J Wilson, Nicole E Blackburn and Ilona McMullan: School of Health Sciences, Ulster University, UK; Paolo Caserotti and Mathias Skjødt: Department of Sport Science and Clinical Biomechanics, University of South Denmark, Denmark; Guillaume Lefebvre: SIEL, Sport initiative et Loisir Bleu association, Straßbourg, France; Denise González: SIEL, Sport initiative et Loisir Bleu association, Barcelona, Spain.

\section{References}


Arnardottir, N.Y., Koster, A., Van Domelen, D.R. et al. (2013). Objective measurements of daily physical activity patterns and sedentary behaviour in older adults: Age, Gene/Environment Susceptibility-Reykjavik Study. Age Ageing, 42, 222-29.

Bandura, A. (1997). Self-efficacy: The exercise of control. New York, NY: W H Freeman.

Bandura, A. (1986). Social foundations of thought and action: A social cognitive theory. Prentice Hall: Englewood Cliffs, NJ, 21.

Bandura, A. (2004). Health promotion by social cognitive means. Health Educational Behaviour, 31, 143-64.

Bangsbo, J., Blackwell, J., Boraxbekk, C. et al., (2019). Copenhagen Consensus statement 2019: physical activity and ageing. British Journal of Sports Medicine. Doi: 11 10.1136/bjsports-2018100451.

Brønd, J.C., \& Arvidsson, D. (2016). Sampling frequency affects the processing of Actigraph raw acceleration data to activity counts. Journal of Applied Physiology, 120(3), 362-69. Doi: 10.1152/japplphysiol.00628.2015.

Bully, P., Sánchez, A., Zabaleta-del-Olmo, E., Pomboa, H., \& Grandes, G. (2015). Evidence from interventions based on theoretical models for lifestyle modification (physical activity, diet, alcohol and tobacco use) in primary care settings: A systematic review. Preventive Medicine, 76, S76S93.

Chief Medical Officers. (CMO) (2019). UK Chief Medical Officers' Physical Activity Guidelines. Downloaded on 8th July 2020 from: https://www.gov.uk/government/publications/physicalactivity-guidelines-uk-chief-medical-officers-report

Choi, L., Liu, Z., Matthews, C. E., \& Buchowski, M. S. (2011). Validation of accelerometer wear and non-wear time classification algorithm. Medicine and Science in Sports and Exercise, 43, 357-64. Doi: 10.1249/MSS.0b013e3181ed61a3.

Craig, P., Dieppe, P., Macintyre, S., et al. (2013). Developing and evaluating complex interventions: the new Medical Research Council guidance. International Journal of Nursing Studies. 50(5): 587-92.

Cunningham, C., O' Sullivan, R., Caserotti, P., \& Tully, M.A. (2020). Consequences of physical inactivity in older adults: A systematic review of reviews and meta-analyses. Scandinavian Journal of Medicine \& Science in Sports, 30(5), 816-27. Doi: 10.1111/sms.13616.

Department of Health and Human Services (DoHHS). (2018). Physical Activity Guidelines for Americans, 2nd edition. Washington, DC: U.S. Department of Health and Human Services, Downloaded on 8th July 2020 from: https://health.gov/sites/default/files/201909/Physical_Activity_Guidelines_2nd_edition.pdf

Department of Health (DOH). (2011). UK physical activity guidelines. Downloaded on 5th September 2019 from: http://www.dh.gov.uk/en/Publicationsandstatistics/Publications/PublicationsPolicyAndGuidance/ DH_127931

Devereux-Fitzgerald, A., Powell, R., Dewhurst, A., French, D.P. (2016). The acceptability of physical activity interventions to older adults: A systematic review and meta-synthesis. Social Science and Medicine, 158,14-23.

Dombrowski, S. U., O'Carroll, R. E., \& Williams, B. (2016). Form of delivery as a key 'active Ingredient' in behaviour change interventions. British Journal of Health Psychology, 21, 733-40. Doi:10.1111/bjhp.12203.

Dyrstad, S.M., Hansen, D.M., Holme et al., (2014). Comparison of self-reported versus accelerometer-measured physical activity. Medicine \& Science in Sports \& Exercise, 46, 99-106. Enders, C.K. (2013). Dealing with missing data in developmental research. Child Development Perspectives, 7, 27-31.

Franco, M.R., Tong, A., Howard, K. et al., (2015). Older people's perspectives on participation in physical activity: a systematic review and thematic synthesis of qualitative literature. British Journal of Sports Medicine, 1-9. Doi: 10.1136/bjsports-2014-094015. 
French, D.P., Olander, E.K., Chisholm, A. \& Mc Sharry, J. (2014). Which Behaviour Change Techniques Are Most Effective at Increasing Older Adults' Self-Efficacy and Physical Activity Behaviour? A Systematic Review, Annals of Behavioral Medicine, 48(2): 225-34. Doi: 10.1007/s12160-014-9593-z.

Fried, L., Prohaska, T., Burholt, V., et al. (2020). A unified approach to loneliness. Lancet, 395 (10218), 114. Doi:10.1016/S0140-6736(19)32533-4.

Giné-Garriga, M., Coll-Planas, L., Guerra, M., et al. (2017). The SITLESS project: exercise Referral schemes enhanced by self-management strategies to battle sedentary behaviour in older adults: study protocol for a randomised controlled trial. Trials, 18, 21. Doi:10.1186/s13063017-1956-X.

Gomes, M., Figueiredo, D., Teixeira, L., et al. (2017). Physical inactivity among older adults across Europe based on the SHARE database. Age and Ageing, 46(1), 71-7. https://doi.org/10.1093/ageing/afw165

Guralnik, J.M., Ferrucci, L., Simonsick, E.M., et al. (1995). Lower extremity function in persons over the age of 70 years as a predictor of subsequent disability. New England Journal of Medicine, 332, 556-61.

Hallal, P.C., Andersen, L.B., Bull, F.C., et al. (2012). Global physical activity levels: surveillance progress, pitfalls, and prospects. The Lancet, 280, 247-57.

Harvey, J.A., Chastin, S.F., \& Skelton, D.A. (2015). How sedentary are older people? A Activity. 23, 471-87.

Hays, R.D., Marshall, G.N., Wang, E.Y.I., et al., (1994). Four-year cross-lagged associations between physical and mental health in the medical outcomes study. Journal of Consulting and Clinical Psychology, 62(3), 441-49.

Health Survey England (HSE) (2017). Health survey for England 2016: Physical activity in adults. Health and Social Care Information Centre. Downloaded on 8th July 2020 from: https://digital.nhs.uk/data-and-information/publications/statistical/health-survey-forengland/2017 Hoyle, R.H. (1995). Structural Equation Modelling: Concepts, issues and applications. Thousand Oaks, CA: Sage Publications, 1-132.

Kwasnicka, D., Dombrowski, S.U., Whited, M., \& Sniehotta, F. (2016). Theoretical explanations for maintenance of behaviour change: a systematic review of behaviour theories. Health Psychology Review, 10(3), 277-96. Doi: 10.1080/17437199.2016.1151372.

Marcus, B.H., Selby, V.C., Niaura, R.S., \& Rossi, J.S. (1992). Self-efficacy and the stages of exercise behavior change. Research Quarterly Exercise Sport. 63(1), 60-6. Doi:10.1080/02701367.1992.10607557.

Michie, S., \& Abraham, C. (2004). Interventions to change health behaviours: evidence-based or evidence-inspired? Psychology Health, 19, 29-49.

Migueles, J. H., Cadenas-Sanchez, C., Ekelund, U., et al. (2017). Accelerometer Data Collection and Processing Criteria to Assess Physical Activity and Other Outcomes: A Systematic Review and Practical Considerations. Sports Medicine, 47, 1821-45. Doi: 10.1007/s40279-017-0716-0. Munafò, M.R., Tilling, K., Taylor, A.E., et al. (2017). Collider scope: when selection bias can substantially influence observed associations. International Journal of Epidemiology, 47(1), 22635.

Murphy, S.L. (2009). Review of physical activity measurement using accelerometers in older adults: considerations for research design and conduct. Preventative Medicine, 48, 108-14.

Murphy, S., Raisanen, L., Moore, et al. (2012). The evaluation of the National Exercise Referral in Wales. Welsh Assembly Government. Journal of Epidemiology Community Health, 66, 74553. Doi:10.1136/jech-2011-200689.

Murray, J.M., Brennan, S.F., French, D.P., et al. (2017). Effectiveness of physical activity interventions in achieving behaviour change maintenance in young and middle-aged adults: $A$ systematic review and meta-analysis. Social Science \& Medicine, 192, 125-33. 
Murray, J. M., Brennan, S. F., French, D. P., et al. (2018). Mediators of behaviour change maintenance in physical activity interventions for young and middle-aged adults: a systematic review. Annals of Behavioral Medicine, 52(6), 513-29. https://doi.org/10.1093/abm/kay012.

McAuley, E., Jerome, G.J., Marquez, D.X., et al. (2003). Exercise self-efficacy in older adults: social, affective, and behavioral influences. Annal of Behavioural Medicine, 25, 1-7.

McAuley, E., Mullen, S.P., \& Szabo, A., et al. (2011). Self-regulatory processes and exercise adherence in older adults: Executive function and self-efficacy effect. American Journal of Preventative Medicine, 41(3), 284-90. Doi: 10.1016/j.amepre.2011.04.014.

McEachan, R., Taylor, N., Harrison, R., et al. (2016). Meta-analysis of the reasoned action approach (RAA) to understanding health behaviors. Annals of Behavioral Medicine, 50, 8 592612.

National Health Service (NHS) Digital Health. (2019). Statistics on obesity, physical activity and diet, England. Downloaded on 3rd June 2020 from: https://digital.nhs.uk/data-and14 information/publications/statistical/statistics-on-obesity-physical-activity-and15 diet/statistics-onobesity-physical-activity-and-diet-england-2019/part-5-adult-physical16 activity.

National Institute of Clinical Excellence (NICE). (2014). Physical activity: exercise referral schemes (PH54). London: NICE.

Pavey, T.G., Anokye, A., Taylor, A.H., et al. (2011). The clinical effectiveness and costeffectiveness of exercise referral schemes: A systematic review and economic evaluation. Health Technology Assessment, 15(44), i-xii, 1-254. Doi: 10.3310/hta15440.

Polit, D. (1996). Data analysis and statistics for nursing research. Appleton \& Lange, Stamford, Connecticut.

Resnick, B., \& Jenkins, L.S. (2000). Testing the reliability and validity of the self-efficacy for exercise scale. Nursing Research, 49(3), 154-59.

Rhodes, R. E., \& Blanchard, C. M. (2007). Just how special are the physical activity cognitions in diseased populations? Preliminary evidence for integrated content in chronic disease prevention and rehabilitation. Annals of Behavioral Medicine, 33, 302-12.

Rhodes, R. E., Janssen, I., Bredin, S. S., et al. (2017). Physical activity: Health impact, prevalence, correlates and interventions. Psychology and Health, 32, 942-75.

Rhodes, R.E., Boudreau, P., Josefsson, W.K., \& Ivarsson, A. (2020). Mediators of physical activity behaviour change interventions among adults: a systematic review and meta-analysis. Health Psychology Review. Doi: 10.1080/17437199.2019.1706614.

Ricardo, L.I.C., Wendt, A., Galliano, L.M., et al. (2019). Number of days required to estimate objectively measured physical activity constructs in different age groups. Doi: 10.1371/journal.pone.0216017.

Rowley, N., Mann, S., Steele, J. et al. (2018). The effects of exercise referral schemes in the United Kingdom in those with cardiovascular, mental health, and musculoskeletal disorders: a preliminary systematic review. BMC Public Health, 18, 949.

Saelens, B.E., Sallis, J.F., Frank, L.D., et al. (2012). Neighborhood environmental and sychosocial correlates of adults' physical activity. Medicine \& Science in Sports \& Exercise, 44, 637-46.

Selig, J.P., \& Little, T.D. (2012). Autoregressive and cross-lagged panel analysis for longitudinal data. Handbook of Developmental Research Methods. Edited by B. Laursen, TD Little, and NA Card. Chapter 16, 265-77. Copyright 2012 by The Guilford Press.

Schwarzer, R. (2008). Modeling health behaviour change: How to predict and modify the 2adoption and maintenance of health behaviours. Applied Psychology, 57,1-29.

Silverman, M. N., \& Deuster, P. A. (2014). Biological mechanisms underlying the role of physical fitness in health and resilience. Interface Focus, 4(5), 20140040. Doi:10.1098/rsfs.2014.0040.

Smith, L., Gardner, B., Fisher, A., et al. (2015). Patterns and correlates of physical activity behaviour over 10 years in older adults: prospective analyses from the English Longitudinal Study of Ageing. BMJ Open, e007423. Doi: 10.1136/bmjopen-2014-007423 
Sports England. (2019). Active Lives survey: Physical inactivity. Downloaded on 8th July 2020 from: $\quad$ https://www.ethnicity-facts-figures.service.gov.uk/health/diet-and-exercise/physicalinactivity/latest

Teixeira, P.J., Carraça, E.V., Marques, M.M., et al. (2015). Successful behavior change in obesity interventions in adults: A systematic review of self-regulation mediators. BMC Medicine, 13, 84.

Umstattd, M.R., Motl, R., Wilcox, S., et al. (2009). Measuring physical activity self-regulation strategies in older adults. Journal of Physical Activity and Health, 6(1), S105-12.

Wade, K.H., Richmond, R. C., \& Smith, G. D. (2018). Physical activity and longevity: how to move closer to causal inference. British Journal of Sports Medicine, 52(14), 1-3.

Ware, J.E., Kosinski, M., \& Keller, S.D. (1996). A 12-Item short-form health survey: Construction of scales and preliminary tests of reliability and validity. Medical Care, 34(3).

Watanabe, K., Kawakami, N., Otsuka, Y., \& Inoue, S. (2018). Associations among workplace environment, self-regulation, and domain-specific physical activities among white-collar workers: a multilevel longitudinal study. International Journal of Behavioral Nutrition and Physical Activity, 15(1). Doi: 10.1186/s12966-018-0681-5.

Wilson, J.J., Skjødt, M., McMullan, I., et al. (2020). Consequences of choosing different settings when processing hip-based accelerometry data from older adults: A practical approach using baseline data from the SITLESS study. Journal for the Measurement of Physical Behaviour, 3(2), 89-99. Doi: 10.1123/jmpb.2019-0037.

Worldwide Health Organisation (WHO). 2002. Active Ageing: A policy Framework. Downloaded on $\quad 9$ th $\quad$ July 2020 from: 9 https://apps.who.int/iris/bitstream/handle/10665/67215/WHO NMH NPH 02.8.pdf;jsessionid=1 E791F15A43F185807F2DBA71A2F9BE2? sequence $=1$

World Health Organization (WHO) (2011). World report on disability. Geneva: World Health Organization. Downloaded on 20th September 2019 from: https://www.who.int/disabilities/world report/2011/en/

World Health Organization (WHO) (2014). Ten facts about physical activity. Geneva. www.who.int/features/factfiles/physical activity/facts/en.

Yuan, K.H., \& Bentler, P.M. (2000). Three likelihood-based methods for mean and covariance structure analysis with non-normal missing data. Sociological Methodology, 165-200.

Young, M.D., Plotnikoff, R.C., Collins, C.E., Callister, R., \& Morgan, P.J. (2014). Social cognitive theory and physical activity: a systematic review and meta-analysis. Obesity reviews, 15, 983-95. Zubala. A., MacGillivray, S., Frost, H., et al. (2017). Promotion of physical activity interventions for community dwelling older adults: A systematic review of reviews. PLoS ONE, 12(7), e0180902. https://doi.org/10.1371/journal.pone.0180902 
Table 1: Descriptive statistics of the SITLESS sample

n or Mean (SD), \%

\begin{tabular}{ll}
\hline Sex & $520,38 \%$ \\
Male & $840,62 \%$ \\
Female & $75.18(6.17$ \\
Age (yrs) & \\
Marital status & $690,53 \%$ \\
Married & $618,47 \%$ \\
Single (including widowed, divorced, separated) & \\
Education Attainment & $320,24 \%$ \\
Primary education & $712,53 \%$ \\
Secondary education & $303,23 \%$ \\
University & $338,25 \%$ \\
Country of residence & $345,25 \%$ \\
Denmark & $356,26 \%$ \\
Germany & $321,24 \%$ \\
Spain & \\
United Kingdom & $23(0.04)$ \\
MVPA per day (minutes) & $51.82(8.86)$ \\
SF12-Mental score & $44.96(9.10)$ \\
SF12-Physical score & $14.12(4.29)$ \\
Self-efficacy score & $31.05(10.57)$ \\
Self-regulation score & \\
Abbreviations: MVPA = Moderate-vigorous Physical Activity; SF-12-heath = 12-item Short Form \\
Survey (SF-12) health questionnaire. \\
Note: descriptive statistics includes missing data
\end{tabular}


Table 2 Direct, indirect, and total effects between moderate to vigorous physical activity (MVPA), self-regulation, and self-efficacy (controlling for sex, age, and self-rated health)

\begin{tabular}{|c|c|c|c|c|c|}
\hline \multirow[t]{2}{*}{ Description } & \multicolumn{3}{|c|}{ Unstandardised Estimate (Standard error) } & \multirow[b]{2}{*}{$\begin{array}{c}\text { Wald value } \\
\text { Group } 1 \& \\
\text { control }\end{array}$} & \multirow[b]{2}{*}{$\begin{array}{c}\text { Wald value } \\
\text { Group } 2 \& \\
\text { control }\end{array}$} \\
\hline & $\begin{array}{l}\text { Intervention } \\
\text { Group } 1\end{array}$ & $\begin{array}{l}\text { Intervention } \\
\text { Group } 2\end{array}$ & $\begin{array}{l}\text { Control } \\
\text { Group }\end{array}$ & & \\
\hline \multicolumn{6}{|l|}{ Direct effects } \\
\hline \multicolumn{6}{|l|}{ Figure 1, path $A$} \\
\hline MVPA between time $1 \& 2$ & $10.70(0.82)^{*}$ & $6.89(0.54)^{\star}$ & $7.61(0.53)^{\star}$ & $8.78^{\star}$ & 0.71 \\
\hline MVPA between time $2 \& 3$ & $0.94(0.08)^{*}$ & $0.91(0.08)^{*}$ & $0.88(0.09)^{*}$ & 0.06 & 0.1 \\
\hline $\begin{array}{l}\text { MVPA between time } 3 \& 4 \\
\text { Figure } 1 \text {, path } B\end{array}$ & $1.04(0.10)^{*}$ & $1.18(0.09)^{\star}$ & $1.17(0.08)^{\star}$ & 0.9 & 0.03 \\
\hline SR between time $1 \& 2$ & $0.51(0.05)^{*}$ & $0.49(0.05)^{\star}$ & $0.67(0.05)^{\star}$ & $5.02^{*}$ & 3.42 \\
\hline SR between time $2 \& 3$ & $1.42(0.15)^{\star}$ & $1.12(0.12)^{\star}$ & $0.87(0.09)^{\star}$ & $11.99^{*}$ & 1.72 \\
\hline $\begin{array}{l}\text { SR between time } 3 \& 4 \\
\text { Figure } 1 \text {, path } C\end{array}$ & $1.09(0.06)^{\star}$ & $1.18(0.10)^{*}$ & $1.13(0.09)^{*}$ & 0.17 & 0.01 \\
\hline SE between time $1 \& 2$ & $0.55(0.07)^{*}$ & $0.52(0.08)^{*}$ & $0.37(0.07)^{*}$ & 3.07 & 0.56 \\
\hline SE between time $2 \& 3$ & $0.17(0.13)^{\star}$ & $0.44(0.09)^{\star}$ & $1.00(0.19)^{\star}$ & 0.05 & $14.97^{*}$ \\
\hline \multicolumn{6}{|l|}{ Figure 1, path $D$} \\
\hline SR time 1 on MVPA time 1 & $0.01(0.01)^{*}$ & $0.01(0.01)$ & $0.01(0.01)$ & - & - \\
\hline SR time 2 on MVPA time 2 & $0.11(0.06)^{\star}$ & $0.10(0.06)$ & $0.03(0.08)$ & - & - \\
\hline SR time 3 on MVPA time 3 & $0.26(0.09)^{*}$ & $0.25(0.06)^{*}$ & $0.23(0.08)^{*}$ & 0.29 & 0.08 \\
\hline $\begin{array}{l}\text { SR time } 4 \text { on MVPA time } 4 \\
\text { Figure } 1 \text {, path } E\end{array}$ & $0.15(0.08)^{*}$ & $-0.00(0.11)$ & $0.07(0.10)$ & - & - \\
\hline SR time 1 on SE time 1 & $0.09(0.03)^{*}$ & $0.19(0.03)^{\star}$ & $0.10(0.03)^{\star}$ & 0.18 & $4.29^{*}$ \\
\hline SR time 2 on SE time 2 & $0.11(0.04)^{*}$ & $0.12(0.05)^{\star}$ & $0.03(0.05)$ & - & - \\
\hline SR time 3 on SE time 3 & $0.02(0.05)$ & $0.12(0.05)^{*}$ & $0.10(0.06)$ & - & - \\
\hline \multicolumn{5}{|l|}{ Figure 1, path $F$} & - \\
\hline SE time 1 on MVPA time 1 & $0.03(0.02)^{*}$ & $-0.00(0.01)$ & $0.01(0.01)$ & - & - \\
\hline SE time 2 on MVPA time 2 & $0.18(0.09)$ & $-0.00(0.12)$ & $0.15(0.12)$ & - & - \\
\hline SE time 3 on MVPA time 3 & $0.04(0.10)$ & $0.01(0.13)$ & $-0.02(0.10)$ & - & - \\
\hline \multicolumn{6}{|l|}{ Figure 1, path 1} \\
\hline SR time 1 on MVPA time 2 & $-0.05(0.05)$ & $-0.08(0.05)$ & $-0.06(0.07)$ & - & - \\
\hline SR time 2 on MVPA time 3 & $-0.28(0.09)^{\star}$ & $-0.15(0.06)^{*}$ & $-0.14(0.08)$ & - & - \\
\hline $\begin{array}{l}\text { SR time } 3 \text { on MVPA time } 4 \\
\text { Figure 1, path } 2\end{array}$ & $-0.07(0.10)$ & $-0.09(0.12)$ & $-0.14(0.13)$ & - & - \\
\hline MVPA time 1 on SR time 2 & $0.07(0.31)$ & $0.44(0.35)$ & $1.14(0.39)^{\star}$ & - & - \\
\hline MVPA time 2 on SR time 3 & $-0.02(0.03)$ & $0.00(0.03)$ & $0.01(0.04)$ & - & - \\
\hline \multicolumn{5}{|l|}{ Figure 1, path 3} & - \\
\hline MVPA time 1 on SE time 2 & $0.01(0.18)$ & $0.35(0.24)$ & $-0.36(0.24)$ & - & - \\
\hline MVPA time 2 on SE time 3 & $-0.00(0.02)$ & $0.00(0.02)$ & $-0.01(0.02)$ & - & - \\
\hline \multicolumn{6}{|l|}{ Figure 1, path 4} \\
\hline SE time 1 on MVPA time 2 & $-0.28(0.12)^{*}$ & $-0.05(0.13)$ & $0.05(0.12)$ & - & - \\
\hline SE time 2 on MVPA time 3 & $-0.13(0.10)$ & $0.06(0.11)$ & $0.05(0.12)$ & - & - \\
\hline $\begin{array}{l}\text { SE time } 3 \text { on MVPA time } 4 \\
\text { Figure } 1 \text {, path } 5\end{array}$ & $0.07(0.10)$ & $-0.04(0.14)$ & $0.12(0.13)$ & - & - \\
\hline SE time 1 on SR time 2 & $0.05(0.08)$ & $0.15(0.10)$ & $-0.02(0.11)$ & - & - \\
\hline SE time 2 on SR time 3 & $0.04(0.10)$ & $-0.08(0.09)$ & $0.09(0.11)$ & - & - \\
\hline \multicolumn{5}{|l|}{ Figure 1, path 6} & - \\
\hline SR time 1 on SE time 2 & $-0.04(0.03)$ & $-0.07(0.05)$ & $0.03(0.05)$ & - & - \\
\hline SR time 2 on SE time 3 & $-0.06(0.06)$ & $-0.03(0.05)$ & $-0.04(0.06)$ & - & - \\
\hline SR time 3 on SE time 4 & $-0.03(0.06)$ & $-0.21(0.07)^{\star}$ & $-0.24(0.10)^{*}$ & - & 0.00 \\
\hline \multicolumn{6}{|l|}{$\begin{array}{l}\text { Total and indirect effects } \\
\text { Fiqure 1, path }\left(E^{\star} F\right)+(D)\end{array}$} \\
\hline SR time 1 on MVPA time 1 & $0.02(0.01)^{*}$ & $0.01(0.01)$ & $0.01(0.01)$ & - & - \\
\hline SR time 2 and MVPA time 2 & $0.13(0.06)^{\star}$ & $0.10(0.06)$ & $0.03(0.08)$ & - & - \\
\hline SR time 3 on MVPA time 3 & $0.26(0.09)^{*}$ & $0.25(0.06)^{\star}$ & $0.22(0.07)^{\star}$ & 0.03 & 0.40 \\
\hline & & $0.01(0.10)$ & $0.06(0.10)$ & - & - \\
\hline \multicolumn{6}{|c|}{ Figure 1, path $\left(D^{*} A\right)+\left(E^{\star} F+A\right)+\left(B^{*} D\right)+\left(B+E^{*} F\right)+\left(E^{*} C+F\right)$} \\
\hline SR time 1 on MVPA time 2 & $1.01(0.28)^{*}$ & $0.41(0.21)^{\star}$ & $0.42(0.31)$ & - & - \\
\hline SR time 2 on MVPA time 3 & $1.85(0.54)^{\star}$ & $1.38(0.34)^{\star}$ & $0.87(0.34)^{\star}$ & 0.47 & $4.00^{*}$ \\
\hline SR time 3 on MVPA time 4 & $1.40(0.51)^{*}$ & $0.94(0.56)$ & $1.04(0.58)$ & - & - \\
\hline
\end{tabular}


Figure 1, time 1 to 4 (summary total effect)

$\begin{array}{llll}\begin{array}{l}\text { SE time } 1 \text { on MVPA time } 4 \\ \text { via MVPA time 1 }\end{array} & 0.34(0.16)^{*} & -0.02(0.10) & 0.08(0.10) \\ \begin{array}{l}\text { SR time } 1 \text { on MVPA time } \\ \text { via SE time 1 }\end{array} & 0.01(0.01) & -0.00(0.02) & 0.01(0.02) \\ \begin{array}{l}\text { SR time } 1 \text { on MVPA time 4 } \\ \text { V }\end{array} & 0.15(0.06)^{*} & 0.05(0.04) & 0.07(0.04)\end{array}$

via MVPA time 1

Note: *statistical significance at $\mathrm{p}=0.05$ level.

Abbreviations: MVPA = Moderate-vigorous physical activity; SR=self-regulation; SE=self-efficacy; SF-12-heath = 12-item Short Form Survey (SF-12) health questionnaire; Time 1 = baseline; Time 2 = intervention completion at 4 months; Time $3=12$-month follow-up; Time 4 = 18-month follow-up

Figure 1 Longitudinal effects between moderate to vigorous physical activity, self-regulation, and self-efficacy

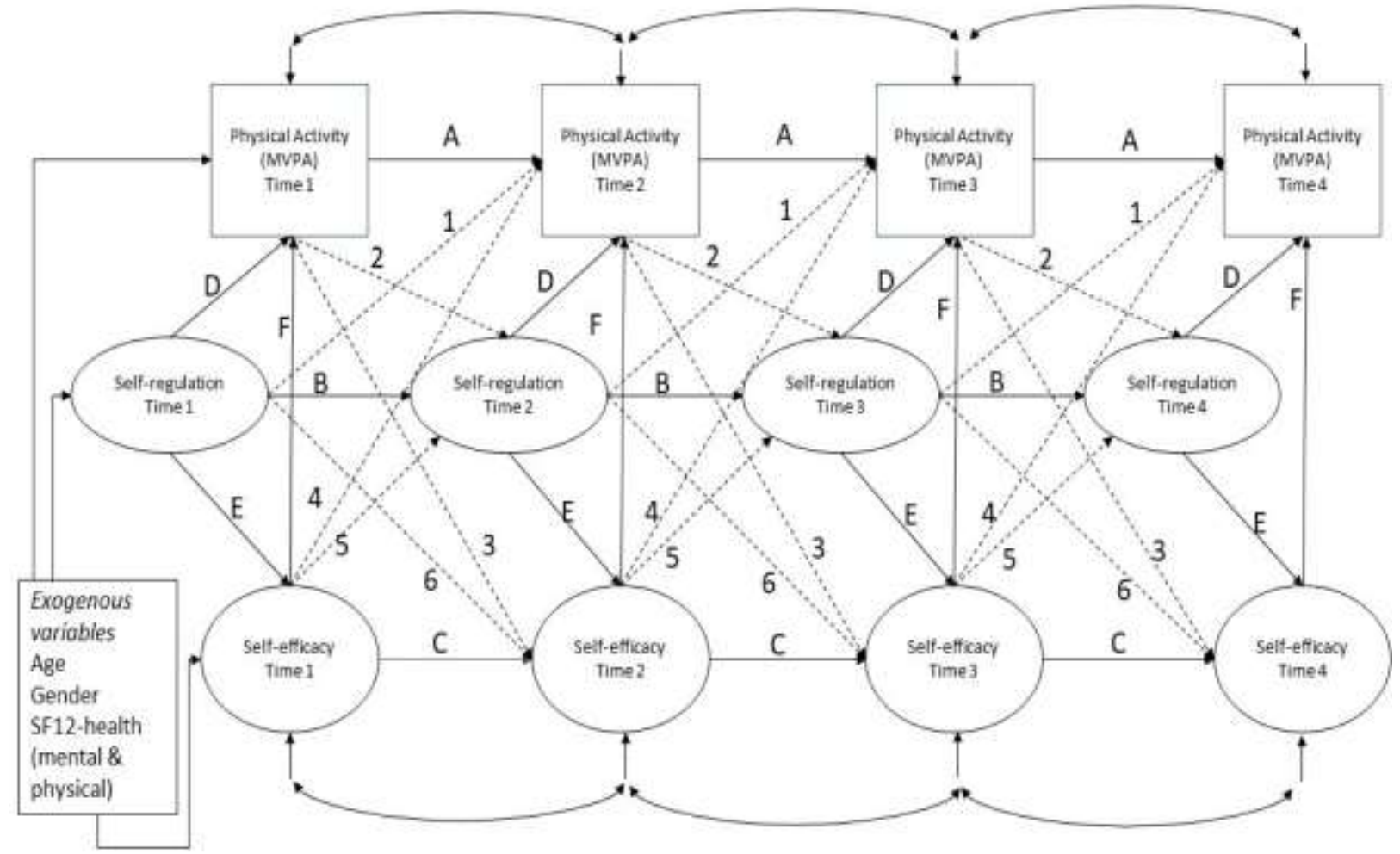

Note: MVPA = Moderate-vigorous. Physical Activity; Time 1= baseline; Time 2 = intervention completion at 4 months;

Time 3 = 12-month follow-up; Time $4=18$-month follow-up; SF-12-heath $=12$-item Short Form Survey health questionnaire 